\title{
Characteristic of the vasorlaxant action of the talatisamine alkaloid and its derivatives
}

\author{
Mirzayeva Yu.T. ${ }^{1 *}$, Usmanov P.B. ${ }^{2}$, Omonturdiyev S.Z. ${ }^{1}$, Ibragimov E.B. ${ }^{1}$ and Abrayeva Z.Ch. ${ }^{2}$ \\ ${ }^{1}$ Institute of Biophysics and Biochemistry, National University of Uzbekistan, Tashkent, Uzbekistan. \\ ${ }^{2}$ Institute of Chemistry of Plant Substances, Uzbek Academy of Sciences, Tashkent, Uzbekistan.
}

*Corresponding Author: Mirzayeva Yu.T, Institute of Biophysics and Biochemistry, National University of Uzbekistan, Tashkent, Uzbekistan Received date: December 30, 2020; Accepted date: January 04, 2021; Published date: March 02,2021

Citation: Mirzayeva Yu.T. Usmanov P.B. Omonturdiyev S.Z. 1Ibragimov E.B. and Abrayeva Z.Ch. (2021) Characteristic of the vasorlaxant action of the talatisamine alkaloid and its derivatives J. Pharmaceutics and Pharmacology Research. 4(2); DOI: 10.31579/2693-7247/0/27

Copyright: (C) 2021, Mirzayeva Yu.T, This is an open access article distributed under the Creative Commons Attribution License, which permits unrestricted use, distribution, and reproduction in any medium, provided the original work is properly cited.

\begin{abstract}
The aim of our research is to study the effect relaxant action of diterpenoid alkaloids talatisamine, 14-Obenzoylthalatisamine and 14-O-acetylthalatisamine was studied using isolated rat aortic rings. Alkaloids significantly and dose-dependently inhibited contraction of the aortic rings caused by high $\mathrm{KCl}$ content. At the same time, under these conditions, alkaloids significantly reduced $\mathrm{Ca} 2+$-induced contraction of the aortic rings. The relaxing effects of alkaloids are significantly suppressed by verapamil, a potent potentiometer-dependent $\mathrm{Ca} 2+$ channel blocker. The alkaloids also significantly reduced norepinephrine-induced aortic ring contraction in normal as well as $\mathrm{Ca} 2+$ free Krebs solutions. The data obtained indicate that talatisamine, 14benzoylthalatisamine and 14-O-acetylthalatisamine exhibit a pronounced relaxant effect in almost the same way in the case of contraction induced by a high content of $\mathrm{KCl}$ and norepinephrine. The mechanism of the relaxant action of alkaloids is probably complex and may include suppression of $\mathrm{Ca} 2+$ influx through voltagedependent and receptor-driven $\mathrm{Ca} 2+$ channels, as well as inhibition of $\mathrm{Ca} 2+$ transport in the sarcoplasmic reticulum.
\end{abstract}

Keywords: aorta, ion channels, receptors, phenylephrine, alkaloids

\section{Introduction}

$\mathrm{Ca} 2+$ ions play a leading role in ensuring the functional activity of blood vessel SMC. As in heart cells, the contractile activity of SMCs depends on $[\mathrm{Ca} 2+] \mathrm{i}$, however, the mechanisms involved in its regulation in SMCs have their own characteristics. In this case, the dominant role is also played by potential-dependent $\mathrm{Ca} 2+-$ channels of the plasma membrane, the activation of which provides the flow of $\mathrm{Ca} 2+$ ions into the cytoplasm of the SMC, the amount of which is sufficient to initiate the contractile process [1]. In addition to voltage-dependent $\mathrm{Ca} 2+$ channels, the supply of $\mathrm{Ca} 2+$ from the extracellular environment to the $\mathrm{SMC}$ is also provided by a supply - detectable and receptor-gated $\mathrm{Ca} 2+$ channels, as well as a $\mathrm{Na}+\mathrm{Ca} 2+$ exchanger [2]. In this case, a prerequisite for the activation of stock-operated channels is the depletion of $\mathrm{Ca} 2+$ ions in the SR. As the name suggests, the work of receptor-gated $\mathrm{Ca} 2+$ channels is controlled by receptors, which interact with specific hormones and mediators to control the work of these channels [3]. At the same time, mediators and hormones activate $G$ proteins through specific receptors, which control the work of various ion channels and enzymes. In particular, in SMCs such activation of phospholipase $\mathrm{C}$ is accompanied by the production of inositol 1,4,5triphosphate (IP3), which interacts with the receptor (IP3R) on the CP membrane, activates the release of $\mathrm{Ca} 2+$ and causes an increase in $[\mathrm{Ca} 2+]$ $\mathrm{i}$ in their cytoplasm [4].

We have previously found that the alkaloid 14-O-benzoylthalatizamine (14-O-BT), a derivative of the diterpenoid alkaloid talatizamine isolated from the plant Aconitum talassicum, effectively relaxes the preparations of the aorta, previously contracted by $\mathrm{KC1}$ [5]

Thus, the results of this series of experiments indicate that the modification of the structure of talatizamine by introducing benzoyl or acetyl groups at positions $\mathrm{C}(14)$ is accompanied by a significant increase in the relaxant activity of their derivatives (Fig.1) Such an increase in the relaxant activity of talatizamine derivatives is apparently due to an increase in their lipophilicity and, accordingly, membrane activity, which is characteristic of the introduction of aromatic groups (benzoyl and acetyl) into the structure of diterpenoid alkaloids ([6],).

In the course of further characterization of the mechanism underlying the relaxant action of talatizamine and its derivatives, their effects were studied under various experimental conditions.

\section{Materials and methods}

All animal care and experimental procedures were approved by the Committee for Animal Experiments of Institute of Biophysics and Biochemistry at the National University of Uzbekistan.

After brief anesthesia with sodium pentobarbital, rat was decapitated and the thoracic aorta was isolated. The connective tissue was removed and rings $3 \mathrm{~mm}$ long were mounted vertically under isometric conditions in a $5 \mathrm{ml}$ organ bath perfused with Krebs solution containing (in $\mathrm{mM}$ ): $\mathrm{NaCl}$ 118.3, $\mathrm{KCl}$ 4.7, $\mathrm{CaCl} 2$ 2.5, MgSO4 1.2, NaH2PO4 1.2, $\mathrm{NaHCO} 3$ 25.0, EGTA 1.0 and glucose $11.1(\mathrm{pH} 7.35)$. Krebs solution was maintained at 
$37 \pm 0.5^{\circ} \mathrm{C}$ and continuously bubbled with $\mathrm{O} 2 / \mathrm{CO} 2$ mixture $(95 \% / 5 \%)$. An initial load of $1 \mathrm{~g}$ was applied and maintained throughout a $60 \mathrm{~min}$ equilibration period. During equilibration the bathing solution was changed every 15 min with readjustment of baseline tension, when necessary. Tension was recorded on a pen recorder (Endim 621.02 Germany) via force-displacement transducers (FT03, Grass Instrument, $\mathrm{Ma}$, USA). To assess the participation of the $\mathrm{Na}+\mathrm{Ca} 2+$ exchanger in the relaxant action of alkaloids, we studied their effect on the contraction of the rat aortic rings induced by Krebs solution with a low $\mathrm{Na}+$ content. The low-Na+ Krebs solution was obtained by replacing $118 \mathrm{mM}$ of $\mathrm{NaCl}$ with iso-osmolar amount of choline chloride. In these experiments after equilibration period in normal Krebs solution the viability of aortic rings was tested by $\mathrm{KCl}(50 \mathrm{mM})$ or phenylephrine $(1 \mu \mathrm{M})$. After this procedure, the aortic rings were repeatedly washed with normal Krebs solution, and when the baseline tension was re-established the aortic rings were exposed to low-Na+ Krebs solution containing $10 \mu \mathrm{M}$ verapamil, and steady contraction was obtained.All reagents were of analytical grade and were obtained from Sigma Chemical Co (St Louis, Mo, USA). All values are expressed as mean \pm standard error of mean (S.E.M.). Student's $t$ test was used for unpaired variants. $\mathrm{P}<0.05$ was considered statistically significant.

\section{Results and its discussion}

In preliminary experiments, it was found that talatizamine, 14-Obenzoylthalatisamine and 14-O-acetylthalatisamine in a wide range of concentrations did not effect the basal tone of rat aortic preparations. However, in further experiments, we found that the studied alkaloids effectively relax the rat aorta preparations, previously contracted with 50 $\mathrm{mM} \mathrm{KCl}$, i.e., they have a relaxing effect. At the same time, the relaxing effect was more pronounced in 14-O-benzoylthalatisamine and 14-Oacetylthalatisamine began to manifest itself already at its concentration of $10 \mu \mathrm{M}$ and $15 \mu \mathrm{M}$, while the relaxant effect of talatizamine was less pronounced and was manifested only at its concentration of $50 \mu \mathrm{M}$. The relaxant effect of alkaloids was dose-dependent, and with an increase in their concentration in the range of $10-250 \mu \mathrm{M}$, the contraction force of the rat aorta preparation induced by $50 \mathrm{mM} \mathrm{KCl}$ decreased from $28.1 \square 2.2$ to $93 \square 3.4 \%$ (Fig.1). The IC50 value, the concentration at which 14-Obenzoylthalatisamine and 14-O-acetyltalatisamin relaxed the aorta preparation by $50 \%$, was $79.5 \mu \mathrm{M}$ and $98.9 \mu \mathrm{M}$, respectively. In contrast to 14-O-BT and 14-O-AT, the dependence of the relaxant effect of talatizamine on its concentration was less pronounced, and the maximum relaxation of the aorta preparation to $42.8 \square 2.5 \%$ was observed at a concentration of $750 \mu \mathrm{M}$ (Fig. 1).

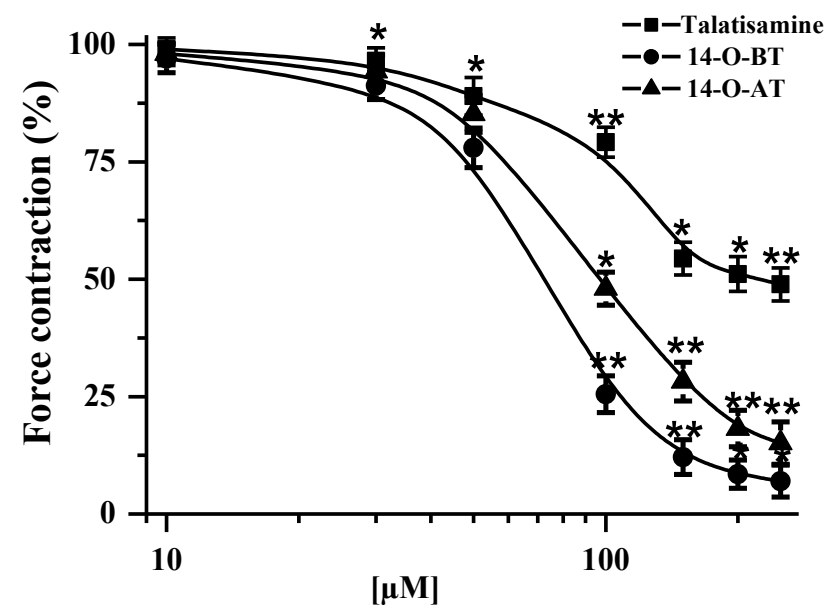

Figure 1. Concentration-dependent effects talatisamine, 14-benzoylthalatisamine and 14-O-acetylthalatisamine rat aortic rings.

Concentration-response curves to alkaloids were determined in rat aortic rings pre-contracted with $\mathrm{KCl}(50 \mathrm{mM}$;). Data are expressed as a percentage of the contraction induced by $\mathrm{KCl}(50 \mathrm{mM})$. Values are mean $\pm \operatorname{SEM}(\mathrm{n}=6) . * \mathrm{P}<0.05, * * \mathrm{P}<0.01$, compared with control.

Considering that the $\mathrm{KCl}$-induced contraction of the rat aorta is mainly provided by the activation of voltage-dependent $\mathrm{Ca} 2+$ channels of the plasmolemma of the SMC and $\mathrm{Ca} 2+$ ions coming through them, it can be assumed that the observed relaxant effect of talatizamine, 14-O-BT and 14-O-AT are possibly realized as a result of blocking these channels by them. At the same time, by blocking these channels and suppressing the entry of $\mathrm{Ca} 2+$ ions into the SMC, the studied alkaloids, apparently, cause a decrease in the intracellular level of $\mathrm{Ca} 2+$ ions, which leads to relaxation of the rat aorta preparations. To test this assumption, we studied the dependence of the relaxant action of the studied alkaloids on the concentration of $\mathrm{Ca} 2+$ ions in the incubation medium.

It is known that in solutions containing no $\mathrm{Ca} 2+$ ions, hyperpotassium solutions do not cause contractions of aortic preparations, and the cumulative addition of $\mathrm{Ca} 2+$ ions under these conditions is accompanied by the development of contractions that reach the control amplitude at 2.5 $\mathrm{mM} \mathrm{CaCl} 2$ [7]. We found that during incubation of rat aorta preparations in calcium-free Krebs solutions in the presence of $14-\mathrm{O}-\mathrm{BT}$ and $50 \mathrm{mM}$ $\mathrm{KCl}$, the addition of $\mathrm{Ca} 2+$ ions also stimulated the development of contractile responses, which, however, were significantly less in amplitude than the responses, registered in the control in the absence of 14-O-BT (Fig. 2).

In particular, in the presence of $250 \mu \mathrm{M} 14-\mathrm{O}-\mathrm{BT}$ and 14-O-AT, the addition of $2.5 \mathrm{mM} \mathrm{CaCl} 2$ to the calcium-free solution caused a contraction of the aorta preparation, which was $83.8 \pm 3.9 \%$ and $70.8 \pm 4.2 \%$, less reduction recorded in the absence of alkaloids. Under similar experimental conditions, in the presence of talatizamine $(250 \mu \mathrm{M})$, the addition of $2.5 \mathrm{mM} \mathrm{CaCl} 2$ caused a contraction, which was $48 \pm 4.1 \%$ less in amplitude compared to the contraction in the control without alkaloid (Fig. 2). The results of these experiments convincingly indicate that the relaxant effect of the studied alkaloids under conditions of $\mathrm{KCl}$ induced contracture is associated with the suppression of the transport of $\mathrm{Ca} 2+$ ions from the extracellular medium into the cytoplasm of the SMC through the voltage-dependent $\mathrm{Ca} 2+-$ channels of the plasma membrane. 


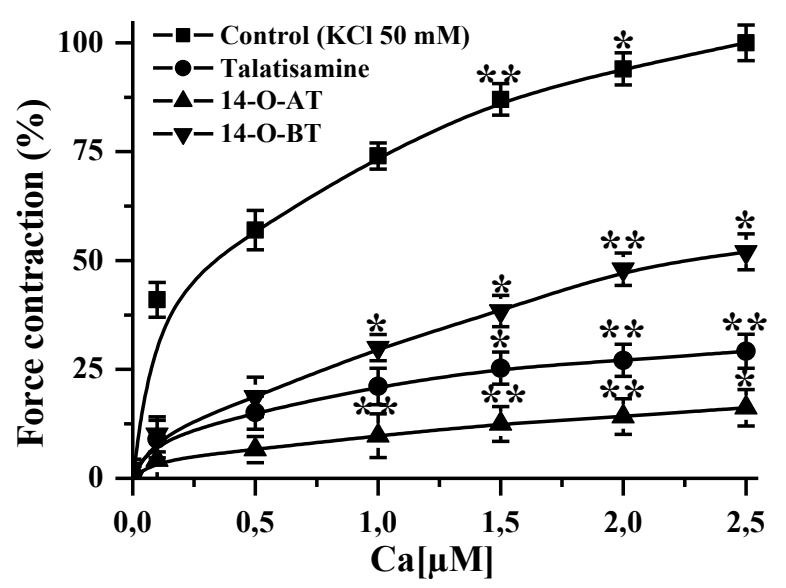

Figure 2. Dependence of the relaxant action of the alkaloids talatizamine, 14-O-benzoylthalatizamine and 14-O-acetylthalatizamine on the concentration of $\mathrm{Ca} 2+$ ions in the incubation medium.

The force of contraction of the rat aorta preparation induced by $50 \mathrm{mM}$ $\mathrm{KCl}$ was taken as $100 \%$. Values are mean $\pm \operatorname{SEM}(\mathrm{n}=6) . * \mathrm{P}<0.05,{ }^{*} * \mathrm{P}<$ 0.01 , compared with control.

In order to clarify the participation of L-type $\mathrm{Ca} 2+$-channels in providing the relaxant action of talatizamine, 14-O-BT and 14-O-AT, the effect of the blocker of these channels verapamil (Ver) on their effects was studied. In these experiments, it was found that in the presence of $0.1 \mu \mathrm{M}$ (Ver), a concentration corresponding to its IC50, the studied alkaloids retained the ability to suppress $\mathrm{KCl}$-induced contractions of the aorta, but to a lesser extent than in its absence. At the same time, 14-O-BT $(250 \mu \mathrm{M})$ and 14O-AT $(250 \mu \mathrm{M})$ additionally suppressed the strength of the aorta contractions induced by $\mathrm{KCl}$, to $31.5 \pm 3.7 \%$ and $33.1 \pm 4.1 \%$ of the control, respectively (Fig. 3,). From these results, it follows that the relaxant action of 14-O-BT and 14-O-AT alkaloids may be based on the blockade of Ltype $\mathrm{Ca} 2+$-channels. However, the retention of the relaxant effect of the studied alkaloids in the presence of VP indicates that, along with the blockade of L-type $\mathrm{Ca} 2+$-channels, other mechanisms of $\mathrm{Ca} 2+$ ion transport into the SMC can be involved in its provision.

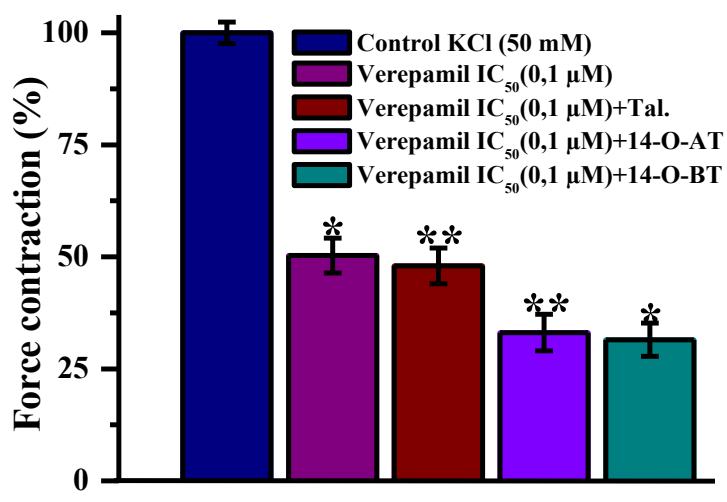

Figure 3. Influence of verapamil on the relaxant action of talatizamine, 14-O-BT and 14-AT. The force of contraction of the rat aorta preparation induced by $50 \mathrm{mM} \mathrm{KCl}$ was taken as $100 \%$. Values are mean \pm SEM $(\mathrm{n}=6)$. $* \mathrm{P}<0.05,{ }^{*} * \mathrm{P}<0.01$, compared with control.

In contrast to 14-O-BT and 14-O-AT, the addition of talatizamine (750 $\mu \mathrm{M})$ under similar conditions did not lead to additional relaxation of the rat aorta preparation.

An important role in the regulation of $\mathrm{Ca} 2+$ homeostasis in SMC, along with voltage-dependent $\mathrm{Ca} 2+$ channels of the L-type, is also played by receptor-gated $\mathrm{Ca} 2+$ channels, which are activated upon stimulation of $\alpha$ adrenergic receptors [8]. In this regard, to assess the effect of the studied alkaloids on receptor-gated $\mathrm{Ca} 2+$ channels, we studied their effects on the contractions of aortic preparations induced by the $\alpha$-adrenergic receptor agonist phenylephrine (PE). PE induces contractions of the aorta, which, in the presence of verapamil, are mainly provided by $\mathrm{Ca} 2+$ ions entering the SMC through receptor-gated $\mathrm{Ca} 2+$ channels [9]. In our experiments, PE $(1 \mu \mathrm{M})$ in the presence of verapamil $(0.1 \mu \mathrm{M})$ induced aortic contractions, the force of which was $10.9 \pm 2.3 \%$ less than the force of contractions caused by it in the absence of verapamil. The addition of alkaloids 14-O-BT and 14-O-AT under these conditions led to a significant suppression of the strength of PE-induced contractions of the aorta, which decreased by $68.4 \pm 3.1 \%$ and $63.6 \pm 3.3 \%$ of the control. respectively (Figure 4, A). 

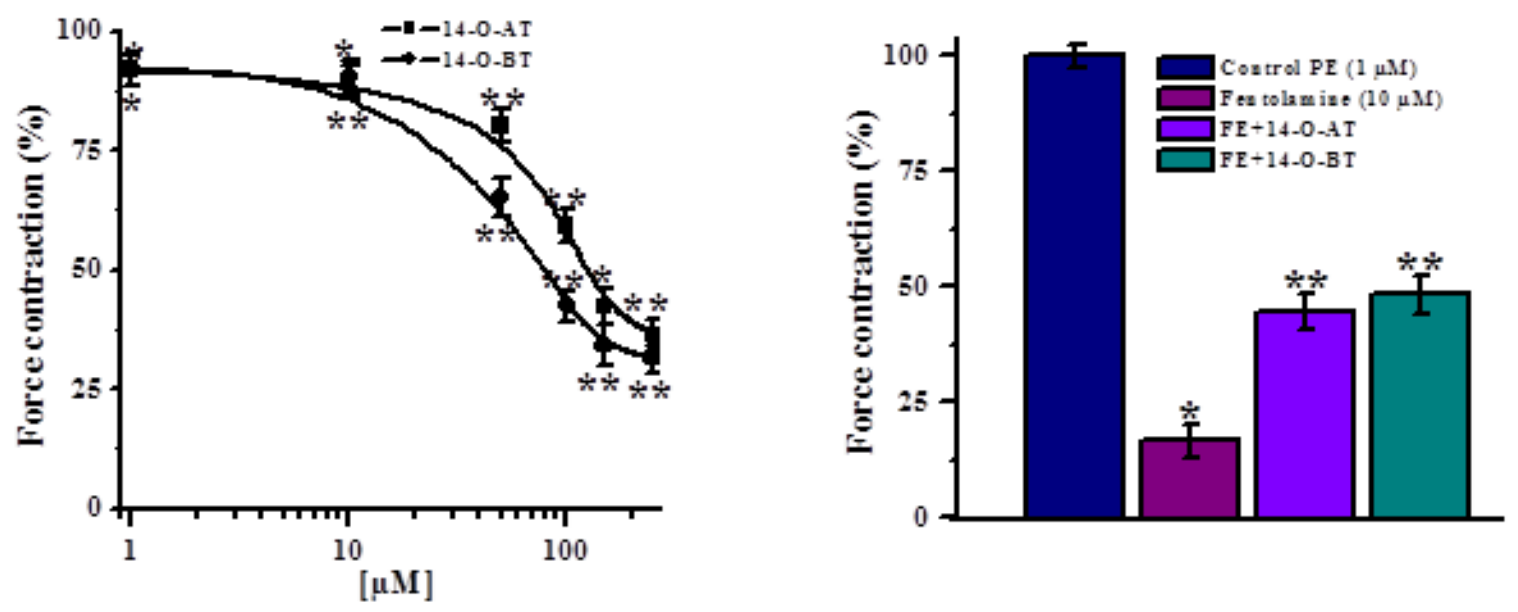

Figure 4. Effect of alkaloids 14-O-BT and 14-O-AT on phenylephrine-induced contractions of the rat aorta.

A. dose-dependent effect of 14-O-BT and 14-O-AT on rat aortic contractions induced by $1 \mu \mathrm{M}$ PE in the presence of $0.1 \mu \mathrm{M}$ verapamil. On the ordinate, the force of aortic contraction, expressed as a percentage of the force induced by $1 \mu \mathrm{M}$ PE in the absence of verapamil and taken as $100 \%$. The abscissa is the concentration of alkaloids. B. - the effect of phentolamine $(10 \mu \mathrm{M})$ on the relaxant effect of $14-\mathrm{O}-\mathrm{BT}$ and $14-\mathrm{O}-\mathrm{AT}(*$ $\mathrm{p}<0.05, * * \mathrm{p}<0.01 ; \mathrm{n}=5)$.

The IC50 values obtained for $14-\mathrm{O}-\mathrm{BT}$ and $14-\mathrm{O}-\mathrm{AT}$ were $80.6 \mu \mathrm{M}$ and $128 \mu \mathrm{M}$, respectively. These results indicate that the observed effect of the studied alkaloids may be due to the blockade of receptor-gated $\mathrm{Ca}^{2+}$ channels. This is confirmed by experiments with a blocker of $\alpha$-adrenergic receptors - phentolamine, in the presence of which the effects of alkaloids 14-O-BT and 14-O-AT on PE-induced aortic contractions decreased by $44.7 \pm 4.0 \%$ and $48.7 \pm 4.3 \%$, respectively, from the control obtained in the absence of phentolamine (Fig. 4,B). These results indicate that the

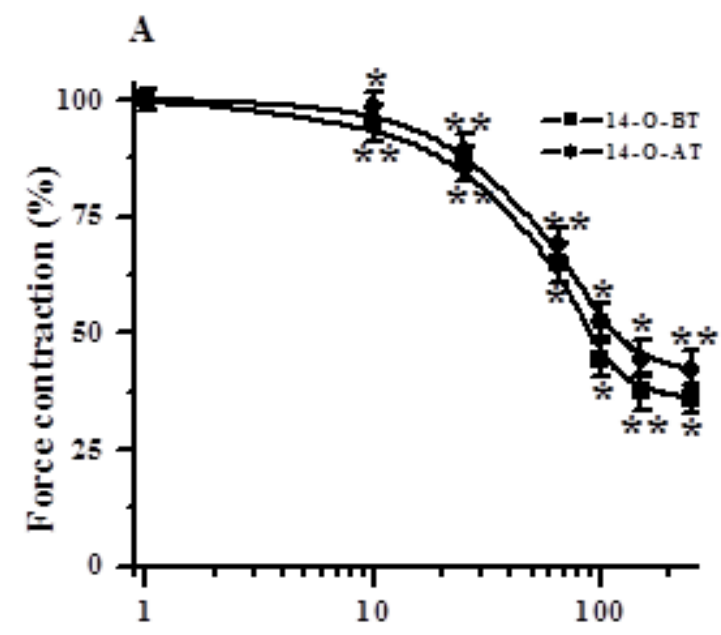

Does not contain Na+ ions. A, B - dose-dependent effect of 14-O-BT and 14-O-AT on rat aortic contractions induced by Krebs solution without $\mathrm{Na}+$ ions. On the ordinate axis, the force of aortic contraction, expressed as a percentage of the force induced without $\mathrm{Na}+$ solution and taken as $100 \%$. The abscissa is the concentration of alkaloids. B- Influence of KB$\mathrm{R} 7943(10 \mu \mathrm{M})$ on the relaxant effect of $14-\mathrm{O}-\mathrm{BT}$ and $14-\mathrm{O}-\mathrm{AT}(* \mathrm{p}$ $<0.05$, ** $\mathrm{p}<0.01 ; \mathrm{n}=6$ ). blockade of receptor-gated $\mathrm{Ca}^{2+}$-channels may also be involved in providing the relaxant effect of the studied alkaloids. At the same time, an important role in the regulation of the contractile activity of smooth muscles by the $\alpha$-adrenergic receptor is also played by the $\mathrm{Na}^{+} / \mathrm{Ca}^{2+}$ exchange of the plasma membrane of the SMC [10].

It was found that the alkaloids 14-O-BT and 14-O-AT significantly suppress the force of aortic contraction induced by a $\mathrm{Na}^{+}$-free solution in the presence of which it decreased to $28.3 \pm 3.6 \%$ and $30.1 \pm 4.1 \%$ of control, respectively (Fig.5. A,B). The $I C_{50}$ values obtained from the results of these experiments were for 14-O-BT and 14-O-AT, $82.3 \mu \mathrm{M}$ and $107.8 \mu \mathrm{M}$, respectively.

These data indicate that the alkaloids 14-O-BT and 14-O-AT effectively suppress the contractions of the aorta induced by the $\mathrm{Na}^{+}$free solution, which are provided by $\mathrm{Ca}^{2+}$ ions entering the SMC through the $\mathrm{Na}^{+} / \mathrm{Ca}^{2+}$ exchanger.

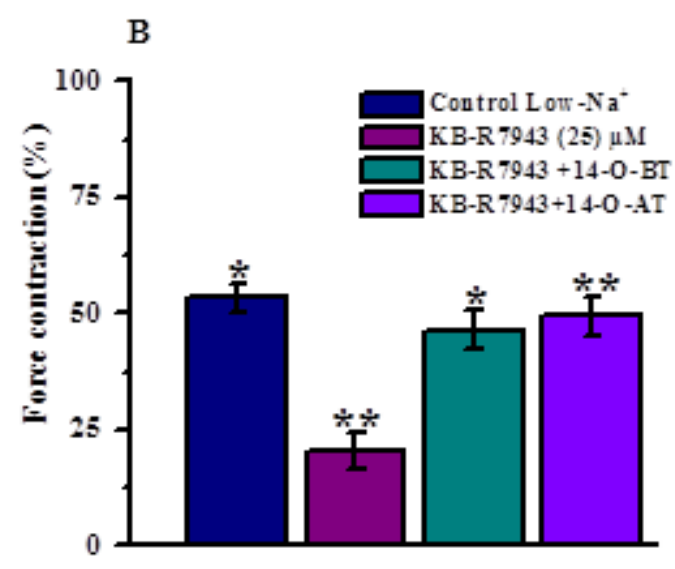

This is confirmed in experiments with KB-R7943 blocker of the $\mathrm{Na}+\mathrm{Ca} 2+$ exchanger, in the presence of which the effects of 14-O-BT and 14-O-AT alkaloids on aortic contractions induced by $\mathrm{Na}+$-free solution decreased to $46.3 \pm 4.2 \%$ and $49.4 \pm 4.5 \%$ of the control obtained in the absence of KB-R7943, respectively (Fig. 5, C). 


\section{Conclusions}

Analysis of the results of these experiments showed that the alkaloids 14O-BT and 14-O-AT equally effectively suppress the contractions of the aorta induced by the no-Na+ solution, as evidenced by their close IC50 values. The close IC50 values obtained using two different methods of activation of aortic contractions, which are mainly provided by $\mathrm{Ca} 2+$ ions coming through the $\mathrm{Na}+\mathrm{Ca} 2+$ exchanger, are convincing evidence of the involvement of this mechanism in providing the relaxant action of 14-OBT and 14-O-AT. The data obtained in this series of experiments allow us to conclude that, in providing the relaxant effect of alkaloids 14-O-BT and 14-O-AT, along with the blockade of voltage-dependent $\mathrm{Ca} 2+-$ channels of the L-type and receptor-gated $\mathrm{Ca} 2+$-channels, an important the blockade of the $\mathrm{Na}+/ \mathrm{Ca} 2+$ exchanger of the SMC may also play a role.

\section{Acknowledgments}

This work was supported by a grant $\Phi$ A- $\Phi-6-004$ from the Coordinating Committee for Development of Science and Technology under the Cabinet of Ministers of the Republic of Uzbekistan.

\section{Conflict of interest}

The authors have declared that no conflict of interest exists.

\section{References}

1. Cribbs L.L. (2001) Vascular Smooth Muscle Calcium Channels.Could T be a target. Circ. Res. Vol (89). P. 560-567.

2. Sanders K.M. (2001) Signal transduction in smooth muscle: mechanisms of calcium handling in smooth muscles. J. Appl. Physiol. Vol (91) P. 1438-1449.
3. Jaggar J.H., Porter V., Nelson M.T. (2000) Calcium sparks in smooth muscle. Am. J. Physiol. Vol (278). P. 235-256.

4. Laporte R., Hui A., Laher I. (2004) Pharmacological modulation of sarcoplasmic reticulum function in smooth muscle. Pharmacol. Rev. Vol (56) P. 439-513.

5. Mirzayeva Yu.T., Usmanov P. B., Sultankhodjaev M. N. (2014) Characteristics of the relaxant action of diterpenoid alkaloids talatizamine and 14-O-benzoylthalatizamine. Uzbekiston Biology Journal. № 4.C.3-7.

6. Ameri A. (1998) Structure-dependent inhibitory action of the Aconitum alkaloids 14-O-benzoyltalitasamine and talatisamine in rat hippocampal slices. Naunyn Schmiedebergs Arch. Pharmacol. Vol (357) -P.585-592.

7. Nishimura K., Ota M., Ito K. (2002) Existence of two components in the tonic contraction of rat aorta mediated by alpha 1-adrenoceptor activation. British Journal of Pharmacology, Vol. (102), pp. 215-221.

8. McFadzean I., Gibson A. (2002) The developing relationship between receptor-operated and store-operated calcium channels in smooth muscle. British Journal of Pharmacology. Vol. (135) P. 1-13.

9. Wier W.G., Morgan K.G. (2003) Alpha1- adrenergic signaling mechanism in contraction of resistance arteries. Rev. Physiol. Biochem. Pharmacol. Vol (150) P. 91-139.

10. Iwamoto T., Kita S., Zhang J., Blaustein M.P., Arai Y., Yoshida S., Wakimoto K., Komuro I., Katsuragi T. (2004) Salt-sensitive hypertension is triggered by $\mathrm{Ca} 2+$ entry via $\mathrm{Na}+/ \mathrm{Ca} 2+$ exchanger type-1 in vascular smooth muscle. Nat Med. Vol 10(11). - P. 1193-1199. 